Published in final edited form as:

Sleep Med. 2020 October ; 74: 57-65. doi:10.1016/j.sleep.2020.05.031.

\title{
SLEEP-DISORDERED BREATHING IN CYSTIC FIBROSIS
}

\author{
Aarti Shakkottai, M.D., M.S. ${ }^{1,2}$, Samya Z. Nasr, M.D., C.P.I. ${ }^{2}$, Fauziya Hassan, M.B.B.S., \\ M.S. ${ }^{1,2}$, Sanaya Irani ${ }^{2}$, Louise M. O'Brien, Ph.D., M.S. ${ }^{1,3,4}$, Ronald D. Chervin, M.D., M.S. ${ }^{1}$ \\ ${ }^{1}$ Sleep Disorders Center and Department of Neurology, Michigan Medicine, Ann Arbor, MI \\ 2Pediatric Pulmonology, Department of Pediatrics and Communicable Diseases, Michigan \\ Medicine, Ann Arbor, Ml \\ ${ }^{3}$ Department of Obstetrics and Gynecology, Michigan Medicine, Ann Arbor, MI \\ ${ }^{4}$ Department of Oral and Maxillofacial Surgery, Michigan Medicine, Ann Arbor, MI
}

\section{Abstract}

Introduction: Cystic fibrosis (CF) is a life-shortening, genetic disease that affects approximately 30,000 Americans. Although patients frequently report snoring, mouth breathing, and insomnia, the extent to which sleep-disordered breathing (SDB) may underlie these complaints remains unknown.

Methods: Single-center retrospective review of polysomnography results from referred patients with and without CF individually-matched (1:2) for age, gender, race, and body mass index (BMI).

Results: Mean ages were $8.0 \pm 5.2(\mathrm{sd})$ and $35.9 \pm 12.9$ years, among 29 children and 23 adults with $\mathrm{CF}$ respectively. The $\mathrm{CF}$ and non-CF groups were well-matched in age and BMI. Subjects with vs. without $\mathrm{CF}$ had 3 times greater odds of moderate-severe SDB (apnea-hypopnea index (AHI) $\geq 5$ in children, $\geq 15$ in adults) $(\mathrm{p}=0.01)$. Nocturnal oxygen saturation nadir $\left(\right.$ Minimum $\left.\mathrm{SpO}_{2}\right)$ was lower among $\mathrm{CF}$ vs. non-CF groups $(\mathrm{p}=0.002)$. For every 1-unit increase in AHI, the decline in Minimum $\mathrm{SpO}_{2}$ was larger for subjects with vs. without $\mathrm{CF}$ ( $\mathrm{p}=0.05$ ). In subjects with $\mathrm{CF}$, forced expiratory volume in 1 second percent predicted (FEV1 PPD) was associated with Minimum $\mathrm{SpO}_{2}$ (Pearson $\mathrm{r}=0.68, \mathrm{p}<0.0001)$ but not AHI $(\mathrm{r}=-0.19, \mathrm{p}=0.27)$. For every 1-unit increase in AHI,

Address for Correspondence: Aarti Shakkottai, M.D., M.S., Sleep Disorders Center and Department of Neurology, Michigan Medicine, 1500 E. Medical Center Drive, C728 Med Inn Building, Ann Arbor, MI 48109-5845, Business Phone: 734-936-9068, Business Fax: 734-936-5377, aartik@med.umich.edu.

CRediT Author Statement

Aarti Shakkottai: Conceptualization, Methodology, Investigation, Formal Analysis, Writing - Original Draft; Samya Nasr: Conceptualization, Methodology, Investigation, Writing - Review \& Editing, Supervision; Fauziya Hassan: Conceptualization, Methodology, Writing - Review \& Editing, Supervision; Sanaya Irani: Investigation, Writing - Review \& Editing; Louise O'Brien: Conceptualization, Methodology, Writing - Review \& Editing, Supervision; Ronald Chervin: Conceptualization, Methodology, Writing - Review \& Editing, Supervision.

Publisher's Disclaimer: This is a PDF file of an unedited manuscript that has been accepted for publication. As a service to our customers we are providing this early version of the manuscript. The manuscript will undergo copyediting, typesetting, and review of the resulting proof before it is published in its final form. Please note that during the production process errors may be discovered which could affect the content, and all legal disclaimers that apply to the journal pertain.

Conflicts of Interest: Dr. Chervin has the following disclosures: Member, Board of Directors, International Pediatric Sleep Association; editor and author, UpToDate. None of the authors have any relevant conflicts of interest to disclose.

This work was performed at the Michigan Medicine Sleep Disorders Center at the University of Michigan. 
magnitude of decline in Minimum $\mathrm{SpO}_{2}$ was larger for those with low vs. normal FEV1 PPD $(\mathrm{p}=0.01)$.

Conclusion: Severity of SDB may be worse among referred patients with vs. without CF. The SDB may modify the relationship between CF lung disease and nocturnal hypoxemia. Markers of lung disease severity including lung function do not predict SDB severity, suggesting the need for routine polysomnography to screen for this sleep disorder.

\section{Summary}

Study Rationale: Little is known about the frequency or severity of sleep-disordered breathing (SDB) in patients with cystic fibrosis (CF) despite recurrent complaints of insomnia, snoring, and mouth breathing. The adverse health impact of SDB could create particular concern for individuals with $\mathrm{CF}$, who already confront a life-limiting illness.

Impact: Patients with vs. without CF may have more severe SDB. Furthermore, SDB could contribute to some of the differences in sleep quantity and quality between $\mathrm{CF}$ and non-CF groups. The relationship between CF lung disease and nocturnal hypoxemia may be modified by the presence of SDB. Testing for SDB may help identify a modifiable risk factor for significant morbidity and mortality among patients with $\mathrm{CF}$.

\section{Introduction}

The detrimental effects of sleep-disordered breathing (SDB) on the mood, behavior, academic performance, health, and quality of life of children has been well-documented ${ }^{1-7}$. In children with respiratory diseases, where the frequency of SDB, including obstructive sleep apnea (OSA) is particularly high, the presence of this condition is associated with more respiratory symptoms, greater healthcare utilization, worse quality of life and health outcomes $^{8-10}$.

Cystic fibrosis (CF) is a chronic, life-shortening, genetic respiratory disease that affects approximately 1 in 3400 live births among Caucasian-Americans ${ }^{11}$. The hallmark of the disease is thick airway secretions leading to impaired mucous clearance, recurrent respiratory infections, and a progressive decline in pulmonary function that culminates in respiratory failure ${ }^{12}$. Pulmonary hypertension from chronic hypoxemia, or low oxygen saturations, is another cause of premature death ${ }^{12,13}$. The average life expectancy for an individual with CF is currently 41 years ${ }^{11}$.

Children with CF frequently endorse restless sleep, trouble breathing during sleep, and daytime sleepiness ${ }^{14-19}$. Data from sleep questionnaires suggest that $30-60 \%$ snore; $40-$ $65 \%$ have difficulties breathing during sleep, including mouth breathing; and 50-75\% have daytime sleepiness ${ }^{16-19}$. Children with $\mathrm{CF}$, as compared to their healthy peers, have a greater frequency of anxiety and depression ${ }^{14,20}$. Impairments in attention, memory, and executive functioning have also been reported in children with $\mathrm{CF}^{21,22}$. Inferior performance in areas of serial reaction and simple arithmetic have been reported in adults with CF in comparison to healthy controls. The same paper also identified significant differences in subjective and objective sleep quality between the groups ${ }^{23}$. Yet, whether SDB could be responsible for any of these complaints has not been thoroughly evaluated. 
Polysomnographic data, largely from places outside the United States, suggest that children with CF have a higher frequency of SDB as compared to age-matched, healthy controls ${ }^{24}$. Moderate-severe SDB, defined as an apnea-hypopnea index (AHI) $\geq 5$, has been reported in $33 \%$ of young children with $\mathrm{CF}^{24}, 13 \%$ of children $2-14$ years of age ${ }^{25}$, and $8 \%$ of adolescents with $\mathrm{CF}^{26}$. Two small polysomnographic studies $(\mathrm{n}=10,25)$ from the United States compared data from children with CF to historic, age-matched controls. However, neither the children with CF nor the controls in either study met criteria for a diagnosis of $\mathrm{SDB}^{27,28}$. Interestingly, none of the children, in any of the studies including the ones that identified a higher frequency of SDB among children with CF, were screened for symptoms of SDB prior to polysomnography. Similar data, on the frequency of SDB, among adults with $\mathrm{CF}$ is lacking.

Children with CF who have OSA, as compared to others who do not have this co-morbidity, have lower oxygen saturations $\left(\mathrm{SpO}_{2}\right)$ at night ${ }^{19,24,25,29,30}$. Both the baseline or average $\mathrm{SpO}_{2}$ across the night $\left(\right.$ Mean $\mathrm{SpO}_{2}$ ) and the $\mathrm{SpO}_{2}$ nadir (Minimum $\mathrm{SpO}_{2}$ ) are reduced in subjects with OSA ${ }^{19,30}$. Frequency of desaturation episodes and duration of hypoxemia $\left(\mathrm{SpO}_{2}<90 \%\right.$ in children) as a percentage of the total sleep time are both higher in the OSA vs. non-OSA group ${ }^{30}$. A moderate negative association has also been reported between the awake resting $\mathrm{SpO}_{2}$ and OSA severity in children with $\mathrm{CF}^{17,31}$. Although adults with $\mathrm{CF}$ tend to have worse nocturnal hypoxemia, whether this is related to severity of the SDB is currently unknown.

Nocturnal hypercapnia, defined as an end-tidal or transcutaneous carbon dioxide $\left(\mathrm{CO}_{2}\right)$ value $250 \mathrm{mmHg}$, is observed with regularity among adults with $\mathrm{CF}$, especially in the setting of supplemental oxygen for treatment of nocturnal hypoxemia ${ }^{32-35}$. Although this is less of a concern among children with $\mathrm{CF}$, who largely have normal $\mathrm{CO}_{2}$ levels during wakefulness and sleep ${ }^{17,27}$, they nevertheless have higher $\mathrm{CO}_{2}$ values in comparison to agematched, healthy peers ${ }^{16}$. Whether $\mathrm{CO}_{2}$ levels are elevated among $\mathrm{CF}$ subjects with vs. without OSA is yet to be uncovered.

The forced expiratory volume in 1 second as a percent predicted (FEV1 PPD) based on age, gender, race, and height is a measure of lung function that is commonly used as a marker of CF lung disease ${ }^{36,37}$. The FEV1 PPD, and, in particular, its rate of decline over time, strongly correlate with mortality among those with $\mathrm{CF}^{38-40}$. Associations between FEV1 PPD and various sleep variables have been identified in children with CF. The FEV1 PPD is positively associated with sleep efficiency and negatively associated with frequency of arousals ${ }^{15,16,41}$. Both sleep efficiency and duration predict FEV1 PPD, independent of age, gender and body mass index (BMI) ${ }^{15,41}$. The potential association between AHI and FEV1 PPD has also been explored, given that both are independently linked to nocturnal hypoxemia ${ }^{25}$. However, neither of the two studies that looked into this relationship found significant associations ${ }^{17,31}$. Of note, in both studies most of the subjects had either a normal AHI or only mild SDB.

The objective of the present study was to assess the frequency and severity of SDB in children and adults with and without $\mathrm{CF}$, who have been referred due to concerns for SDB. The potential relationships between AHI and daytime markers of CF lung disease such as 
FEV1 PPD were explored. We also evaluated differences in sleep duration, sleep fragmentation and other standard polysomnographic measures of sleep between patients with and without $\mathrm{CF}$, and the potential impact of SDB on these variables. Finally, we compared the two groups with regards to severity of nocturnal hypoxemia and hypercapnia.

\section{Methods}

We performed a retrospective review of polysomnographic data from January $1^{\text {st }} 2009$ September $30^{\text {th }} 2017$ in patients with CF who were referred to the Michigan Medicine Sleep Disorders Center. Only patients who had undergone a baseline (diagnostic) sleep study were considered. Individuals without CF but similarly referred to the Sleep Disorders Center for diagnostic polysomnography during 2009-2017 were also identified. All subjects were referred for polysomnography due to a concern for SDB.

In both groups, patients with chromosomal anomalies such as Trisomy 21, chronic respiratory failure, defined as the need for chronic ventilation including non-invasive ventilation, neuromuscular conditions including cerebral palsy, myelomeningocele, Chiari malformations, muscular dystrophy, craniosynostosis, and upper airway anomalies including cleft lip/palate and Pierre-Robin sequence were excluded. The CF and non-CF groups were matched with respect to age, gender, race, and body mass index (BMI). The groups were matched for age in years. Subjects less than 2 years of age were matched for age in months such that the cases and controls were no more than 2.5 months apart in age. Adult subjects with and without $\mathrm{CF}$ were matched within 2 points of their BMI. Pediatric subjects with and without $\mathrm{CF}$ were matched within 1 point of their BMI. Each subject with $\mathrm{CF}$ was individually matched to two subjects without the disease. Whenever possible, the $\mathrm{CF}$ and non-CF subjects had their polysomnography in the same year. The study was approved by the University of Michigan Medical Institutional Review Board (IRBMED).

Polysomnographic studies were conducted at an American Academy of Sleep Medicine (AASM)-accredited center and scored by registered technologists using the AASM Scoring Manual. The 2007 version was used to score studies from 2009-2013. Version 2.0 was used from 2013-2014, 2.1 in 2014, 2.2 in 2015, 2.3 in 2016 and 2.4 in 2017. The non-CF controls were chosen from studies performed in the same year with the exception of 14 controls whose studies were performed in a year with different scoring guidelines as compared to their matched case.

\section{Outcomes}

The primary outcome of interest was difference in SDB severity, as determined by the AHI, between the CF and non-CF groups. An AHI $>1$ in children and $\geq 5$ in adults was used to identify SDB. The SDB was subsequently classified as being moderate-severe if the AHI was $\geq 5$ in children and $\geq 15$ in adults. We examined CF vs. non-CF differences in standard polysomnographic variables, including total sleep time, sleep efficiency, frequency of arousals, wakefulness after sleep onset (WASO), average oxygen saturation across the night (Mean $\mathrm{SpO}_{2}$ ), lowest oxygen saturation attained during the night (Minimum $\mathrm{SpO}_{2}$ ) and cumulative duration of hypoxemia. Hypoxemia was defined as oxygen saturation $<90 \%$ in children and $<88 \%$ in adults. When available, the maximum carbon dioxide (Maximum 
$\mathrm{CO}_{2}$ ) values attained during the night were compared between the $\mathrm{CF}$ and non-CF groups. We also explored associations between AHI and daytime markers of CF lung disease severity, including the FEV1 PPD and Brasfield Score. Of note, subjects with CF who had undergone lung transplantation prior to polysomnography were excluded from these analyses.

The FEV1 PPD is a lung function measure that is obtained once every 3 months in patients with CF $\geq 6$ years. An FEV1 PPD $\geq 80 \%$ is considered normal. The FEV1 PPD obtained within 3 months of the diagnostic polysomnography during a routine clinic visit (not in the setting of an illness) was recorded on all eligible subjects through a review of their medical records. Only lung function data considered acceptable by American Thoracic Society standards was included.

The Brasfield scoring system is based on radiographic findings on a two-view plain chest $\mathrm{x}$ ray. Scores range from 3-25 depending on the extent of the abnormalities, with lower scores indicating worse disease ${ }^{42}$. While there is a degree of subjectivity to the scoring, the Brasfield Score has been repeatedly shown to be sensitive to changes in disease progression, especially among those with moderate-severe CF lung disease. The scores have also been shown to correlate with pulmonary function ${ }^{43,44}$. Chest $\mathrm{x}$-rays obtained within 12 months of the diagnostic polysomnography during a routine clinic visit were identified. A boardcertified pediatric pulmonologist (SZN) scored all of the chest x-rays. The pulmonologist was masked to the results of the pulmonary function testing and polysomnography.

\section{Statistical Methods}

A two-sample t-test was used to verify that the $\mathrm{CF}$ and non-CF groups were well-matched with regards to age and BMI. Conditional logistic regression was used to determine the odds of SDB, defined as AHI $>1$ in children and $\geq 5$ in adults, and the odds of moderate-severe $\mathrm{SDB}$, defined as AHI $\geq 5$ in children and $\geq 15$ in adults. Linear mixed models were used to look at differences in the standard polysomnographic variables between the $\mathrm{CF}$ and non-CF groups. Linear mixed models were also used to study the impact of SDB severity on these differences. These methods were used to account for the paired nature of the data.

Among the subjects with $\mathrm{CF}$, a chi-square test of proportions was used to compare frequency of SDB among children and adults with CF. Pearson correlation was used to examine the relationship between FEV1 PPD (and Brasfield Scores) and AHI, nocturnal oxygen saturation, and the other standard polysomnographic measures of sleep. Linear regression models were used to assess the respective contributions of AHI and FEV1 PPD on nocturnal hypoxemia and sleep fragmentation in subjects with CF. All the analyses were conducted using SAS Version 9.4 (SAS Institute Inc., Cary, NC).

\section{Results}

Twenty-nine children and 23 adults with CF were identified as having undergone diagnostic polysomnography during the study period. Mean ages were $8.0 \pm 5.2$ and $35.9 \pm 12.9$ years among the children and adults with CF respectively. Children with $\mathrm{CF}$, on average, had a BMI percentile $\geq 50 \%$. The BMI was within normal range $\left(18.5-24.5 \mathrm{~kg} / \mathrm{m}^{2}\right)$ even among 
the adults with CF. The non-CF group, which included 58 children and 46 adults, was similar in age and BMI to the subjects with $\mathrm{CF}(\mathrm{p}>0.05$, Table 1). Lung function data were available for 34 subjects with $\mathrm{CF}$, after excluding children too young to perform the test and adults who had undergone lung transplantation prior to their diagnostic polysomnography. Chest x-rays from 36 subjects were assigned Brasfield Scores, after excluding those with a history of lung transplantation and those whose x-rays were obtained only during times of respiratory illness. Both the FEV1 PPD and the Brasfield Score, not surprisingly, were lower in adults as compared to children (Table 2).

\section{SDB among subjects with and without CF}

Forty-one out of the 52 subjects with CF (79\%) and 71 out of the 104 subjects without CF (68\%) met study criteria for SDB (AHI >1 in children and $\geq 5$ in adults). The CF group had 1.9 times greater odds, albeit non-significant of SDB as compared to the non-CF group (95\% CI: $0.8,4.4 ; \mathrm{p}=0.14)$. Sixteen subjects in the CF group (31\%) and 15 subjects in the non-CF group (14\%) had moderate-severe SDB (AHI $\geq 5$ in children and $\geq 15$ in adults). The CF group had 3.0 times greater odds of moderate-severe SDB as compared to the non-CF group (95\% CI: 1.2, 7.3; $\mathrm{p}=0.01$ ). Similar but non-significant trends were observed when the data were analyzed separately in children and adults. Children with vs. without CF had 3.7 times greater odds of any SDB (95\% CI: $0.8,18.2 ; \mathrm{p}=0.1)$ and 2.8 times greater odds of moderatesevere SDB (95\% CI: 0.9, 8.7; $\mathrm{p}=0.07$ ). Adults with vs. without $\mathrm{CF}$ had 1.4 times greater odds of any SDB (95\% CI: $0.5,3.8 ; \mathrm{p}=0.6)$ and 3.3 times greater odds of moderate-severe SDB (95\% CI: $0.8,13.9 ; \mathrm{p}=0.1)$.

We also examined differences in the AHI as a continuous variable. Two subjects in the non$\mathrm{CF}$ control group were noted to be extreme outliers $\left(>3^{\text {rd }}\right.$ quartile $+3 *$ interquartile range) (Supplementary Figure 1). When all subjects were included there were no differences in AHI between subjects with vs. without $\mathrm{CF}(6.8 \pm 5.7$ (SD) vs. $5.8 \pm 8.2$, respectively; $\mathrm{p}=0.36)$. Following appropriate exclusion of these extreme outliers (along with the corresponding $\mathrm{CF}$ case and the second matched control), the differences in AHI between the groups became significant ( $\mathrm{p}=0.029$, Table 3 ). No differences were observed in the obstructive and central apnea indices in either analysis (Table 3). Of note, as logistic regression is robust to outliers, we did not exclude these two extreme outliers in the above analyses of odds for any SDB and moderate-severe SDB in CF vs. non-CF subjects. We also have not excluded these outliers in any of the remaining analyses presented below.

\section{Sleep duration, sleep efficiency, and sleep fragmentation and the impact of SDB}

Subjects with CF, as compared to those without the disease, had a lower sleep duration, poorer sleep efficiency, and greater sleep fragmentation characterized by more arousals and sleep-stage transitions per hour of sleep and a longer duration in WASO (Table 3). These differences between subjects with and without $\mathrm{CF}$ were, in general, more pronounced among the adults than children (Supplementary Table 1). Sleep-onset latency was more prolonged among children with vs. without CF (Supplementary Table 1). However, this same difference was not observed among the adults. 
The differences in sleep duration between subjects with vs. without CF persisted even after accounting for differences in the AHI between the two groups: subjects with CF had 38 minutes less of total sleep duration, on average, as compared to those without the disease $(\beta=-37.8, \mathrm{SE}=7.9, \mathrm{p}<0.0001)$. The potential impact of SDB severity on sleep fragmentation was more complicated. For every 10-point increase in the AHI, the approximate difference between mild and moderate SDB in an adult, subjects with vs. without CF had nearly 4 more sleep-stage transitions and arousals per hour of sleep and spent 20 minutes longer in WASO (Figure 1).

\section{Nocturnal Gas Exchange Parameters and the Impact of SDB Severity}

Nocturnal oxygenation was, not surprisingly, worse among subjects with vs. without CF (Table 3). The differences in the nocturnal oxygen saturation indices between subjects with vs. without CF were more pronounced in adults than children (Supplementary Table 1). Nocturnal capnometry data were available for 25 out of the 52 patients with CF and 44 out of the 104 non-CF controls. The maximum $\mathrm{CO}_{2}$ values attained during the night were 3 $\mathrm{mmHg}$ lower in the $\mathrm{CF}$ vs. non-CF group (Table 3 ). Of note, most of the capnometry results were recorded from children with and without $\mathrm{CF}$, with similar data available for only 4 adults altogether. Furthermore, an association was not observed between maximum $\mathrm{CO}_{2}$ values attained during the night and the AHI $(\mathrm{p}=0.4)$.

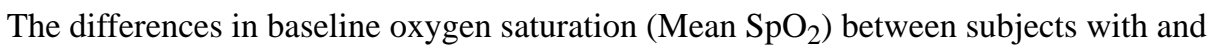
without $\mathrm{CF}$ persisted even after accounting for differences in the $\mathrm{AHI}(\beta=-1.6, \mathrm{SE}=0.3$, $\mathrm{p}<0.0001)$. The presence of $\mathrm{CF}$ appeared to be a modifier in the relationship between the oxygen saturation nadir (Minimum $\mathrm{SpO}_{2}$ ) and the AHI such that for the same increase in AHI, our model found that patients with vs. without $\mathrm{CF}$ had a greater reduction in their Minimum $\mathrm{SpO}_{2}$ ( $\beta$ for the interaction term=-0.17, $\mathrm{SE}=0.09, \mathrm{p}=0.05$ ). A 10-point increase in the AHI was associated with a $3.5 \%$ reduction in the Minimum $\mathrm{SpO}_{2}$ among subjects with $\mathrm{CF}$. Whereas, a similar change in AHI was associated with only a 1.7\% decline in Minimum $\mathrm{SpO}_{2}$ in those without $\mathrm{CF}$.

\section{Relationship between SDB severity and daytime measures of CF lung disease severity}

Frequency of SDB was higher among children with $\mathrm{CF}$ as compared to adults with the disease ( $90 \%$ vs. $65 \%$ respectively; $\mathrm{p}=0.04$ ). The frequency of moderate-severe SDB among children vs. adults showed a similar tendency but the difference did not reach statistical significance ( $38 \%$ vs. $22 \%$ respectively, $\mathrm{p}=0.2$ ). The high frequency of SDB seen among subjects with CF did not appear to be influenced by weight. Nineteen out of the 52 subjects with CF were either overweight or obese (BMI percentile $\geq 85 \%$ or BMI $\geq 25 \mathrm{~kg} / \mathrm{m}^{2}$ ). Frequency of SDB among the 19 subjects was no different from that of subjects with normal weight ( $84 \%$ vs $76 \%$; $\mathrm{p}=0.7$ ). When we focused selectively on the 29 subjects with a BMI percentile $\geq 50 \%$, the magnitude of the difference in SDB frequency between the obese vs normal groups increased but it still did not reach statistical significance (86\% vs $70 \%$; $\mathrm{p}=0.2$ ). Mean FEV1 PPD showed a trend towards being higher among CF subjects with vs. without SDB but did not reach statistical significance ( $82 \%$ vs. $58 \%$ respectively; $\mathrm{p}=0.07$ ). Brasfield Scores were similar among CF subjects with and without SDB (19 vs. 18 
respectively; $\mathrm{p}=0.4)$. Neither the FEV1 PPD nor Brasfield Scores were associated with the AHI (Table 4).

\section{Relationship between sleep duration, sleep efficiency, sleep fragmentation and CF lung disease and the impact of SDB}

Among the subjects with $\mathrm{CF}$, associations were observed, in plausible directions, between FEV1 PPD and sleep duration ( $\mathrm{r}=0.53, \mathrm{p}=0.001)$, sleep efficiency $(\mathrm{r}=0.43, \mathrm{p}=0.01)$, and multiple measures of sleep fragmentation including the Stage-Shifts Index ( $\mathrm{r}=-0.46$, $\mathrm{p}=0.006)$, time spent in WASO $(\mathrm{r}=-0.43, \mathrm{p}=0.01), \%$ total sleep time spent in Non-REM Stage $1(\mathrm{~N} 1)$ sleep $(\mathrm{r}=-0.50, \mathrm{p}=0.002)$ and Non-REM Stage 3 (N3) sleep $(\mathrm{r}=0.41, \mathrm{p}=0.02)$. Brasfield Scores were only associated with \%N3 sleep $(\mathrm{r}=0.35, \mathrm{p}=0.04)$. Neither the FEV1 PPD nor Brasfield Scores were associated with sleep-onset or REM sleep latency, frequency of arousals, or \% total sleep time in Non-REM Stage 2 (N2) or REM sleep (p>0.05).

The associations between FEV1 PPD and \%N1 sleep remained significant even after accounting for differences in the AHI $(\beta=-0.11, \mathrm{SE}=0.04, \mathrm{p}=0.005)$. A significant interaction was noted between the AHI and FEV1 PPD when evaluating their respective impact on the Stage-Shifts-Index ( $\mathrm{p}=0.047$, Figure 2). Based on our model, a 10-point increase in the AHI would result in 4 more sleep-stage transitions per hour of sleep in a CF subject with an FEV1 PPD of 90\% which is in the normal range. In contrast, in an individual with an FEV1 PPD of 70\%, which signifies mild lung disease, the same 10-point increase in AHI would result in 7 more sleep-stage transitions per hour of sleep.

\section{Relationship between nocturnal gas-exchange parameters and daytime CF lung disease measures, and the impact of SDB}

Significant associations were identified between the FEV1 PPD and multiple nocturnal oxygen saturation indices though not the maximum $\mathrm{CO}_{2}$ values attained during sleep (Table 4). However, only 16 of the 34 patients with FEV1 PPD data also had nocturnal capnometry performed. Significant associations were also found between Brasfield Scores and the Mean and Minimum $\mathrm{SpO}_{2}$ and duration of low baseline oxygen saturations (Table 4). Despite having a correlation co-efficient in the small-moderate range $(\mathrm{r}=-0.36)$, the relationship between Brasfield Scores and Maximum $\mathrm{CO}_{2}$ values did not reach statistical significance. However, only 21 out of the 36 subjects with Brasfield Scores also had nocturnal capnography data. No differences were observed in any of the nocturnal oxygenation or capnometry indices between CF subjects who were overweight/obese as compared to those of normal weight $(\mathrm{p}=0.6)$.

The associations between Brasfield Scores and the Minimum $\mathrm{SpO}_{2}$ remained significant even after accounting for differences in the AHI $(\beta=0.49, \mathrm{SE}=0.18, \mathrm{p}=0.008)$. A significant interaction was observed when the effects of AHI and FEV1 PPD on the Minimum $\mathrm{SpO}_{2}$ were evaluated ( $\mathrm{p}=0.01$, Figure 4). Based on our model, a 10-point increase in the AHI would result in a $1.8 \%$ lower Minimum $\mathrm{SpO}_{2}$ in a CF subject with an FEV1 PPD of 90\%. In contrast, a subject with an FEV1 of 70\% would have a 3\% lower Minimum $\mathrm{SpO}_{2}$ for the same 10-point increase in AHI (Figure 3). 


\section{Discussion}

Among 156 patients who were referred for polysomnography over a 9-year period from 2009-2017, the frequency of moderate-severe was significantly higher among those with CF as compared to matched, non-CF controls. Specifically, the individuals with CF had 3-times greater odds of moderate-severe SDB. Furthermore, the presence of SDB had worse statistical impact on sleep duration, sleep fragmentation, and nocturnal oxygenation in the $\mathrm{CF}$ vs. non-CF group. The association of SDB with sleep fragmentation and nocturnal oxygenation were also more pronounced among CF patients with significant lung disease. Yet, neither of the daytime markers of CF lung disease severity (FEV1 PPD and Brasfield chest x-ray scores) were associated with AHI. Given the known relationship between hypoxemia and development of pulmonary hypertension, our findings raise the possibility, though speculative at this point, that early identification of SDB through direct testing or effective screening of patients with CF could improve key outcomes.

This is the first study, to our knowledge, to look at SDB severity and its potential relationship with daytime markers of $\mathrm{CF}$ lung disease severity in patients with $\mathrm{CF}$ who are suspected to have SDB. Both the $\mathrm{CF}$ and non-CF groups were similarly referred for polysomnography due to symptoms of SDB. Nearly $80 \%$ of the patients with CF had SDB, with a higher frequency of disease noted in children vs. adults with CF. Approximately onethird of the patients with CF had moderate-severe SDB. These findings are in line with two other studies that also found SDB in about one-third of children with CF, most of whom were noted to have significant upper airway anomalies including adenotonsillar hypertrophy and chronic rhinosinusitis ${ }^{24,29}$. Additional data on overall frequency and severity of SDB in adults with $\mathrm{CF}$ are still lacking. However, limited polysomnographic data suggest a similar association between rhinosinusitis and frequency of SDB even among adults with $\mathrm{CF}^{26,45}$.

The subjects with $\mathrm{CF}$, as compared to those without the disease, slept less and had more fragmented sleep. Although similar findings have been reported in other studies involving both children and adults with CF, how SDB might affect sleep in patients with CF has never been explored $15,16,18,24,28,46$. We found that patients with CF may be particularly vulnerable to the effects of SDB on sleep fragmentation. A similar change in SDB was associated with much more fragmented sleep (frequent arousals and sleep-stage transitions, and longer duration in WASO) among subjects with vs. without CF. Several factors are recognized to have the potential to affect sleep in patients with $\mathrm{CF}$; these include certain medications, the presence of a nighttime cough, co-morbid conditions such as asthma and CF-related diabetes (CFRD), and gastrointestinal symptoms such as abdominal pain, reflux, and frequent defecation ${ }^{14,15,41}$. In light of our current findings, however, we believe that SDB, a potentially treatable condition, likely merits consideration in this list.

Consistent with existing literature, nocturnal oxygenation was worse among our patients with vs. without $\mathrm{CF}^{16,18,24,26,28,45}$. The impact of $\mathrm{SDB}$ on the Minimum $\mathrm{SpO}_{2}$ was differentially worse among the subjects with $\mathrm{CF}$ as compared to those without the disease. For a similar change in SDB severity, patients with vs. without CF experienced a greater reduction in their oxygen saturation nadir. This is a novel observation. Although prior studies have looked separately at the frequency of nocturnal hypoxemia and SDB severity in 
patients with $\mathrm{CF}^{24,25}$, how the presence of SDB affects nocturnal oxygenation in patients with vs. without $\mathrm{CF}$ has never been examined, to our knowledge.

We also evaluated our study population for the presence of nocturnal hypoventilation. Our patients with $\mathrm{CF}$ had a lower Maximum $\mathrm{CO}_{2}$ value as compared to those without the disease and this did not appear to be related to the severity of the SDB. The clinical significance of finding is still unclear as the magnitude of the difference was only $3 \mathrm{mmHg}$. Furthermore, nocturnal capnometry data was only available for $48 \%$ of patients with CF and about $40 \%$ of the non-CF controls, with the majority being children. We also did not have any information on expiratory tidal volumes, respiratory rates, or whether the capnometry signal was adequate. Nevertheless, this deserves further examination as high daytime and nocturnal $\mathrm{CO}_{2}$ levels have been reported in association with low lung function and pulmonary hypertension in patients with $\mathrm{CF}^{13,45}$.

Interestingly, but nevertheless consistent with the existing literature, neither of our daytime markers of CF lung disease severity were associated with the AHI ${ }^{29,31}$. Weight was also not a significant predictor of the AHI as frequency of SDB was similar among CF subjects who were overweight/obese and those who had normal weight. Although the FEV1 PPD and Brasfield Scores were associated with multiple measures of nocturnal oxygenation, neither appeared to be linked to the Maximum $\mathrm{CO}_{2}$ value attained during the night. Despite a smallmodest correlation $\left(\mathrm{R}=0.36\right.$ ) between Brasfield Scores and the Maximum $\mathrm{CO}_{2}$, this did not reach statistical significance. Whether this lack of a significant relationship is secondary to a limited sample size needs to be explored further. The same 10-point increase in AHI was associated with a nearly $1.5 \%$ lower Minimum $\mathrm{SpO}_{2}$ in subjects with mildly reduced vs. normal lung function. Although not surprising given that individuals with low lung function tend to have reduced pulmonary reserves and consequently a poor response to hypoxemia, our finding nevertheless highlights the need to definitively test or effectively screen individuals with CF, and especially those with severe lung disease, for SDB.

Significant associations were also identified between severity of CF lung disease and sleep duration, sleep efficiency, and multiple measures of sleep fragmentation. Subjects with CF who had reduced lung function also had a shorter sleep duration, poorer sleep efficiency, longer periods of lighter (Stage N1) sleep, and more frequent sleep-stage transitions per hour of sleep. In contrast, subjects with higher Brasfield Scores, which signify the presence of minimal lung disease, spent longer periods in deeper (Stage N3) sleep. A similar 10-point increase in AHI was associated with more frequent sleep-stage transitions, or a higher StageShifts Index, in subjects with mild lung disease as compared to those with normal lung function. For every 10-point increase in the AHI, a subject with an FEV1 of 70\% would potentially have 7 more sleep-stage transitions per hour of sleep, or about 1 transition every 8.5 minutes. Although these relationships are not novel ${ }^{15-18,41}$, the adverse health impact of poor sleep in this population cannot be overstated. Short sleep duration is associated with an increased risk of cardiovascular and all-cause mortality among non-CF adults ${ }^{47}$. Among otherwise healthy children, reduced sleep duration is linked to higher levels of circulating inflammatory markers and an increased risk of hyperlipidemia and insulin resistance ${ }^{48-50}$. Although the role of inflammation in the pathogenesis of $\mathrm{CF}$ has been well established ${ }^{12}$, how the presence of sleep disturbances might influence this process is yet to be explored. 
Whether short sleep duration increases the frequency of CFRD, a known risk factor for morbidity and mortality ${ }^{51}$, is also still unknown. Despite known associations between sleep and lung function, whether poor sleep accelerates lung function decline in patients with $\mathrm{CF}$ is also unclear. Given that these patients already suffer from a life-limiting illness, the potential contributions of diminished sleep quality and quantity may merit additional research.

Our study does have limitations, starting with its retrospective design. Although our comparison subjects were free of $\mathrm{CF}$ and other serious medical conditions, they were not completely healthy. Several had asthma and allergic rhinitis, conditions that have also been independently linked to the presence of sleep disturbances. Although we tried to exclude subjects with severe asthma, this could, nevertheless, have diluted our effect size. Matching the groups for age, gender, race, and BMI prevented an assessment of how these variables might affect differences in SDB between the $\mathrm{CF}$ and non-CF groups. Polysomnographic data from both groups spanned a 9-year period, during which time there were several updates to relevant sections of the American Academy of Sleep Medicine Scoring Manual, leading to the possibility of a scoring drift. However, matching the groups for date of study performance (within 2 years) should have helped to minimize any such effect.

Despite these limitations, the results of this study suggest that sleep-laboratory referred patients with vs. without CF tend to have more severe SDB. Furthermore, severity of SDB may contribute to some of the group differences in sleep fragmentation and nocturnal hypoxemia. Prospective studies with more subjects will be needed to further explore these relationships. In the meantime, we believe our findings do argue for screening of all patients with CF for SDB, especially since neither lung function nor results of pulmonary imaging predict who might be at risk for SDB. The possibility exists that diagnosis and treatment of SDB would help to alleviate nocturnal hypoxemia, and improve sleep quantity and quality, and thereby improve the health of individuals with CF.

\section{Supplementary Material}

Refer to Web version on PubMed Central for supplementary material.

\section{Acknowledgements}

We would like to acknowledge Judy Fetterolf, RPSGT, REEGT and Casey Cox, RPSGT, REEGT for their assistance with the data retrieval. This work was supported by NIH training grants (T32NS007222, F32HL145915).

Funding: Dr. Shakkottai was supported by NIH training grants (T32NS007222, F32HL145915). Dr. Chervin was supported in part by R01 HL105999. None of the other authors had relevant financial support.

\section{Abbreviations:}

AASM

AHI

BMI
American Academy of Sleep Medicine

Apnea-hypopnea index

Body mass index

Sleep Med. Author manuscript; available in PMC 2021 October 01. 


$\begin{array}{ll}\mathrm{CO}_{2} & \text { Carbon dioxide } \\ \text { CF } & \text { Cystic fibrosis } \\ \text { FEV1 PPD } & \text { Forced expiratory volume in one second as a percent predicted } \\ \text { N1 } & \text { Non-Rapid Eye Movement Sleep Stage 1 } \\ \text { N2 } & \text { Non-Rapid Eye Movement Sleep Stage 2 } \\ \text { N3 } & \text { Non-Rapid Eye Movement Sleep Stage 3 } \\ \text { OSA } & \text { Obstructive sleep apnea } \\ \text { SpO } & \text { Oxygen saturation } \\ \text { REM } & \text { Rapid Eye Movement Sleep } \\ \text { SDB } & \text { Sleep-disordered breathing } \\ \text { WASO } & \text { Wakefulness after sleep onset }\end{array}$

\section{References:}

1. Chervin RD, Ruzicka DL, Giordani BJ, et al. Sleep-disordered breathing, behavior, and cognition in children before and after adenotonsillectomy. Pediatrics. 2006;117(4):e769-778. [PubMed: 16585288]

2. Bonuck K, Chervin RD, Howe LD. Sleep-disordered breathing, sleep duration, and childhood overweight: a longitudinal cohort study. J Pediatr. 2015;166(3):632-639. [PubMed: 25499598]

3. Garetz SL, Mitchell RB, Parker PD, et al. Quality of life and obstructive sleep apnea symptoms after pediatric adenotonsillectomy. Pediatrics. 2015;135(2):e477-486. [PubMed: 25601979]

4. O'Brien LM. The neurocognitive effects of sleep disruption in children and adolescents. Child Adolesc Psychiatr Clin N Am. 2009;18(4):813-823. [PubMed: 19836689]

5. O'Brien LM, Mervis CB, Holbrook CR, et al. Neurobehavioral implications of habitual snoring in children. Pediatrics. 2004;114(1):44-49. [PubMed: 15231906]

6. Hunter SJ, Gozal D, Smith DL, Philby MF, Kaylegian J, Kheirandish-Gozal L. Effect of Sleepdisordered Breathing Severity on Cognitive Performance Measures in a Large Community Cohort of Young School-aged Children. Am J Respir Crit Care Med. 2016;194(6):739-747. [PubMed: 26930303]

7. Landau YE, Bar-Yishay O, Greenberg-Dotan S, Goldbart AD, Tarasiuk A, Tal A. Impaired behavioral and neurocognitive function in preschool children with obstructive sleep apnea. Pediatr Pulmonol. 2012;47(2):180-188. [PubMed: 21905262]

8. Marcus CL. Sleep-disordered breathing in children. Am J Respir Crit Care Med. 2001;164(1):1630. [PubMed: 11435234]

9. Goldstein NA, Aronin C, Kantrowitz B, et al. The prevalence of sleep-disordered breathing in children with asthma and its behavioral effects. Pediatr Pulmonol. 2015;50(11):1128-1136. [PubMed: 25461921]

10. Ginis T, Akcan FA, Capanoglu M, et al. The frequency of sleep-disordered breathing in children with asthma and its effects on asthma control. J Asthma. 2017;54(4):403-410. [PubMed: 28060556]

11. Cystic Fibrosis Foundation Patient Registry. 2017 Annual Data Report Bethesda, Maryland: Cystic Fibrosis Foundation;2018.

12. Elborn JS. Cystic fibrosis. Lancet. 2016;388(10059):2519-2531. [PubMed: 27140670]

13. Ziegler B, Perin C, Casarotto FC, Fagondes SC, Menna-Barreto SS, Dalcin PT. Pulmonary hypertension as estimated by Doppler echocardiography in adolescent and adult patients with 
cystic fibrosis and their relationship with clinical, lung function and sleep findings. Clin Respir J. 2016.

14. Shakkottai A, O’Brien LM, Nasr SZ, Chervin RD. Sleep disturbances and their impact in pediatric cystic fibrosis. Sleep Med Rev. 2018.

15. Amin R, Bean J, Burklow K, Jeffries J. The relationship between sleep disturbance and pulmonary function in stable pediatric cystic fibrosis patients. Chest. 2005;128(3):1357-1363. [PubMed: 16162729]

16. Naqvi SK, Sotelo C, Murry L, Simakajornboon N. Sleep architecture in children and adolescents with cystic fibrosis and the association with severity of lung disease. Sleep Breath. 2008;12(1):7783. [PubMed: 17610099]

17. Silva AM, Descalco A, Salgueiro M, et al. Respiratory sleep disturbance in children and adolescents with cystic fibrosis. Rev Port Pneumol (2006). 2016;22(4):202-208. [PubMed: 27052354]

18. Vandeleur M, Walter LM, Armstrong DS, Robinson P, Nixon GM, Horne RS. How Well Do Children with Cystic Fibrosis Sleep? An Actigraphic and Questionnaire- Based Study. J Pediatr. 2017;182:170-176. [PubMed: 28040232]

19. Waters KA, Lowe A, Cooper P, Vella S, Selvadurai H. A cross-sectional analysis of daytime versus nocturnal polysomnographic respiratory parameters in cystic fibrosis during early adolescence. $\mathrm{J}$ Cyst Fibros. 2017;16(2):250-257. [PubMed: 27727099]

20. Quittner AL, Abbott J, Georgiopoulos AM, et al. International Committee on Mental Health in Cystic Fibrosis: Cystic Fibrosis Foundation and European Cystic Fibrosis Society consensus statements for screening and treating depression and anxiety. Thorax. 2016;71(1):26-34. [PubMed: 26452630]

21. Piasecki B, Stanislawska-Kubiak M, Strzelecki W, Mojs E. Attention and memory impairments in pediatric patients with cystic fibrosis and inflammatory bowel disease in comparison to healthy controls. J Investig Med. 2017;65(7):1062-1067.

22. Piasecki B, Turska-Malinska R, Matthews-Brzozowska T, Mojs E. Executive function in pediatric patients with cystic fibrosis, inflammatory bowel disease and in healthy controls. Eur Rev Med Pharmacol Sci. 2016;20(20):4299-4304. [PubMed: 27831643]

23. Dancey DR, Tullis ED, Heslegrave R, Thornley K, Hanly PJ. Sleep quality and daytime function in adults with cystic fibrosis and severe lung disease. Eur Respir J. 2002;19(3):504-510. [PubMed: 11936530]

24. Spicuzza L, Sciuto C, Leonardi S, La Rosa M. Early occurrence of obstructive sleep apnea in infants and children with cystic fibrosis. Arch Pediatr Adolesc Med. 2012;166(12):1165-1169. [PubMed: 23090511]

25. Ramos RT, Santana MA, Almeida Pde C, Machado Ade S Jr, Araujo-Filho JB, Salles C. Nocturnal hypoxemia in children and adolescents with cystic fibrosis. J Bras Pneumol. 2013;39(6):667-674. [PubMed: 24473760]

26. de Castro-Silva C, de Bruin VM, Cavalcante AG, Bittencourt LR, de Bruin PF. Nocturnal hypoxia and sleep disturbances in cystic fibrosis. Pediatr Pulmonol. 2009;44(11):1143-1150. [PubMed: 19824056]

27. Paranjape SM, McGinley BM, Braun AT, Schneider H. Polysomnographic Markers in Children With Cystic Fibrosis Lung Disease. Pediatrics. 2015;136(5):920-926. [PubMed: 26482667]

28. Suratwala D, Chan JS, Kelly A, et al. Nocturnal saturation and glucose tolerance in children with cystic fibrosis. Thorax. 2011;66(7):574-578. [PubMed: 21273357]

29. Ramos RT, Salles C, Gregorio PB, et al. Evaluation of the upper airway in children and adolescents with cystic fibrosis and obstructive sleep apnea syndrome. Int J Pediatr Otorhinolaryngol. 2009;73(12):1780-1785. [PubMed: 19854521]

30. Ramos RT, Salles C, Daltro CH, Santana MA, Gregorio PB, Acosta AX. Sleep architecture and polysomnographic respiratory profile of children and adolescents with cystic fibrosis. J Pediatr (Rio J). 2011;87(1):63-69. [PubMed: 21229190]

31. Veronezi J, Carvalho AP, Ricachinewsky C, et al. Sleep-disordered breathing in patients with cystic fibrosis. J Bras Pneumol. 2015;41(4):351-357. [PubMed: 26398755] 
32. Spier S, Rivlin J, Hughes D, Levison H. The effect of oxygen on sleep, blood gases, and ventilation in cystic fibrosis. Am Rev Respir Dis. 1984;129(5):712-718. [PubMed: 6426355]

33. Gozal D Nocturnal ventilatory support in patients with cystic fibrosis: comparison with supplemental oxygen. Eur Respir J. 1997;10(9):1999-2003. [PubMed: 9311492]

34. Milross MA, Piper AJ, Norman M, et al. Low-flow oxygen and bilevel ventilatory support: effects on ventilation during sleep in cystic fibrosis. Am J Respir Crit Care Med. 2001;163(1):129-134. [PubMed: 11208637]

35. Dobbin CJ, Milross MA, Piper AJ, Sullivan C, Grunstein RR, Bye PT. Sequential use of oxygen and bi-level ventilation for respiratory failure in cystic fibrosis. J Cyst Fibros. 2004;3(4):237-242. [PubMed: 15698941]

36. Harun SN, Wainwright C, Klein K, Hennig S. A systematic review of studies examining the rate of lung function decline in patients with cystic fibrosis. Paediatr Respir Rev. 2016;20:55-66. [PubMed: 27259460]

37. Schluchter MD, Konstan MW, Drumm ML, Yankaskas JR, Knowles MR. Classifying severity of cystic fibrosis lung disease using longitudinal pulmonary function data. Am J Respir Crit Care Med. 2006;174(7):780-786. [PubMed: 16858011]

38. Breuer O, Caudri D, Stick S, Turkovic L. Predicting disease progression in cystic fibrosis. Expert Rev Respir Med. 2018;12(11):905-917. [PubMed: 30173593]

39. McColley SA, Schechter MS, Morgan WJ, Pasta DJ, Craib ML, Konstan MW. Risk factors for mortality before age 18 years in cystic fibrosis. Pediatr Pulmonol. 2017;52(7):909-915. [PubMed: 28436621]

40. Szczesniak RD, Li D, Su W, et al. Phenotypes of Rapid Cystic Fibrosis Lung Disease Progression during Adolescence and Young Adulthood. Am J Respir Crit Care Med. 2017;196(4):471-478. [PubMed: 28410569]

41. Vandeleur M, Walter LM, Armstrong DS, Robinson P, Nixon GM, Horne RSC. What keeps children with cystic fibrosis awake at night? J Cyst Fibros. 2017;16(6):719-726. [PubMed: 28479021]

42. Brasfield D, Hicks G, Soong S, Peters J, Tiller R. Evaluation of scoring system of the chest radiograph in cystic fibrosis: a collaborative study. AJR Am J Roentgenol. 1980;134(6):11951198. [PubMed: 6770630]

43. Cleveland RH, Neish AS, Zurakowski D, Nichols DP, Wohl ME, Colin AA. Cystic fibrosis: a system for assessing and predicting progression. AJR Am J Roentgenol. 1998;170(4):1067-1072. [PubMed: 9530060]

44. Cleveland RH, Neish AS, Zurakowski D, Nichols DP, Wohl ME, Colin AA. Cystic fibrosis: predictors of accelerated decline and distribution of disease in 230 patients. AJR Am J Roentgenol. 1998;171(5):1311-1315. [PubMed: 9798870]

45. Perin C, Fagondes SC, Casarotto FC, Pinotti AF, Menna Barreto SS, Dalcin Pde T. Sleep findings and predictors of sleep desaturation in adult cystic fibrosis patients. Sleep Breath. 2012;16(4):1041-1048. [PubMed: 21948072]

46. Fauroux B, Pepin JL, Boelle PY, et al. Sleep quality and nocturnal hypoxaemia and hypercapnia in children and young adults with cystic fibrosis. Arch Dis Child. 2012;97(11):960-966. [PubMed: 22984185]

47. Yin J, Jin X, Shan Z, et al. Relationship of Sleep Duration With All-Cause Mortality and Cardiovascular Events: A Systematic Review and Dose-Response Meta-Analysis of Prospective Cohort Studies. J Am Heart Assoc. 2017;6(9).

48. Fernandez-Mendoza J, Baker JH, Vgontzas AN, Gaines J, Liao D, Bixler EO. Insomnia symptoms with objective short sleep duration are associated with systemic inflammation in adolescents. Brain Behav Immun. 2017;61:110-116. [PubMed: 28041986]

49. Rudnicka AR, Nightingale CM, Donin AS, et al. Sleep Duration and Risk of Type 2 Diabetes. Pediatrics. 2017;140(3).

50. Kong AP, Wing YK, Choi KC, et al. Associations of sleep duration with obesity and serum lipid profile in children and adolescents. Sleep Med. 2011;12(7):659-665. [PubMed: 21689984]

51. Moheet A, Moran A. CF-related diabetes: Containing the metabolic miscreant of cystic fibrosis. Pediatr Pulmonol. 2017;52(S48):S37-S43. [PubMed: 28714601] 


\section{Highlights:}

- $\quad$ Severity of sleep-disordered breathing (SDB) may be worse in patients with cystic fibrosis (CF)

- $\quad$ Presence of SDB may worsen the impact of CF lung disease on nocturnal hypoxemia

- $\quad$ SDB severity may contribute to the impaired sleep quantity and quality seen in $\mathrm{CF}$ 

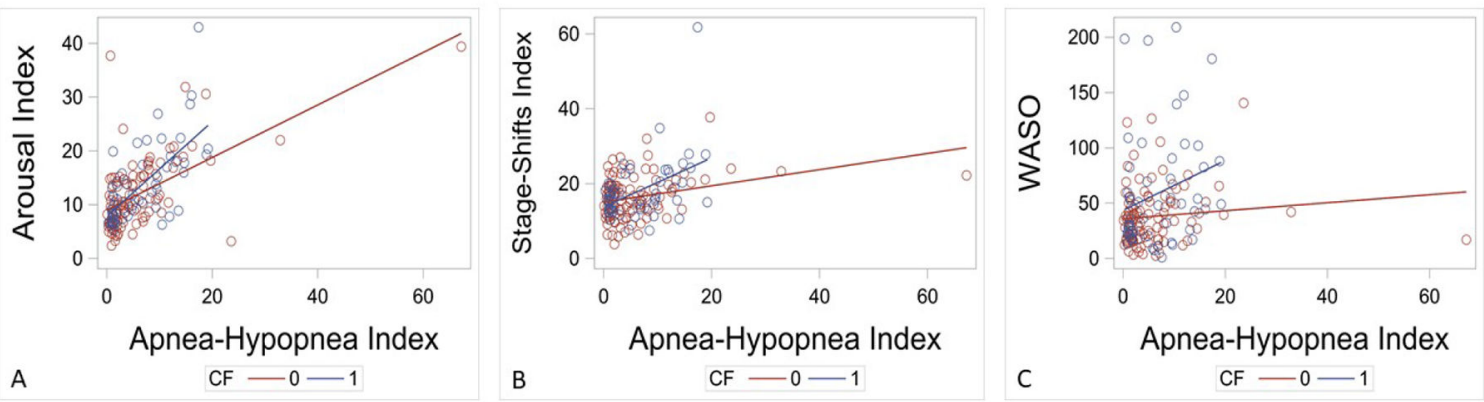

Figure 1: Relationship between sleep fragmentation and apnea-hypopnea index (AHI) in patients with vs. without cystic fibrosis (CF).

Based on linear mixed models, for every 1-unit increase in the AHI, the $\mathrm{CF}(\mathrm{CF}=1)$ vs. non$\mathrm{CF}$ group $(\mathrm{CF}=0)$ had a higher frequency of arousals (arousal index) $(\mathrm{A}: \beta=0.4, \mathrm{SE}=0.1$, $\mathrm{p}=0.01$ ) and sleep-stage transitions (Stage-Shifts Index) $(\mathrm{B}: \beta=0.4, \mathrm{SE}=0.2, \mathrm{p}=0.02)$ per hour of sleep and spent longer in wakefulness after sleep onset (WASO) $(C: \beta=2.0, S E=1.0$, $\mathrm{p}=0.04)$. 


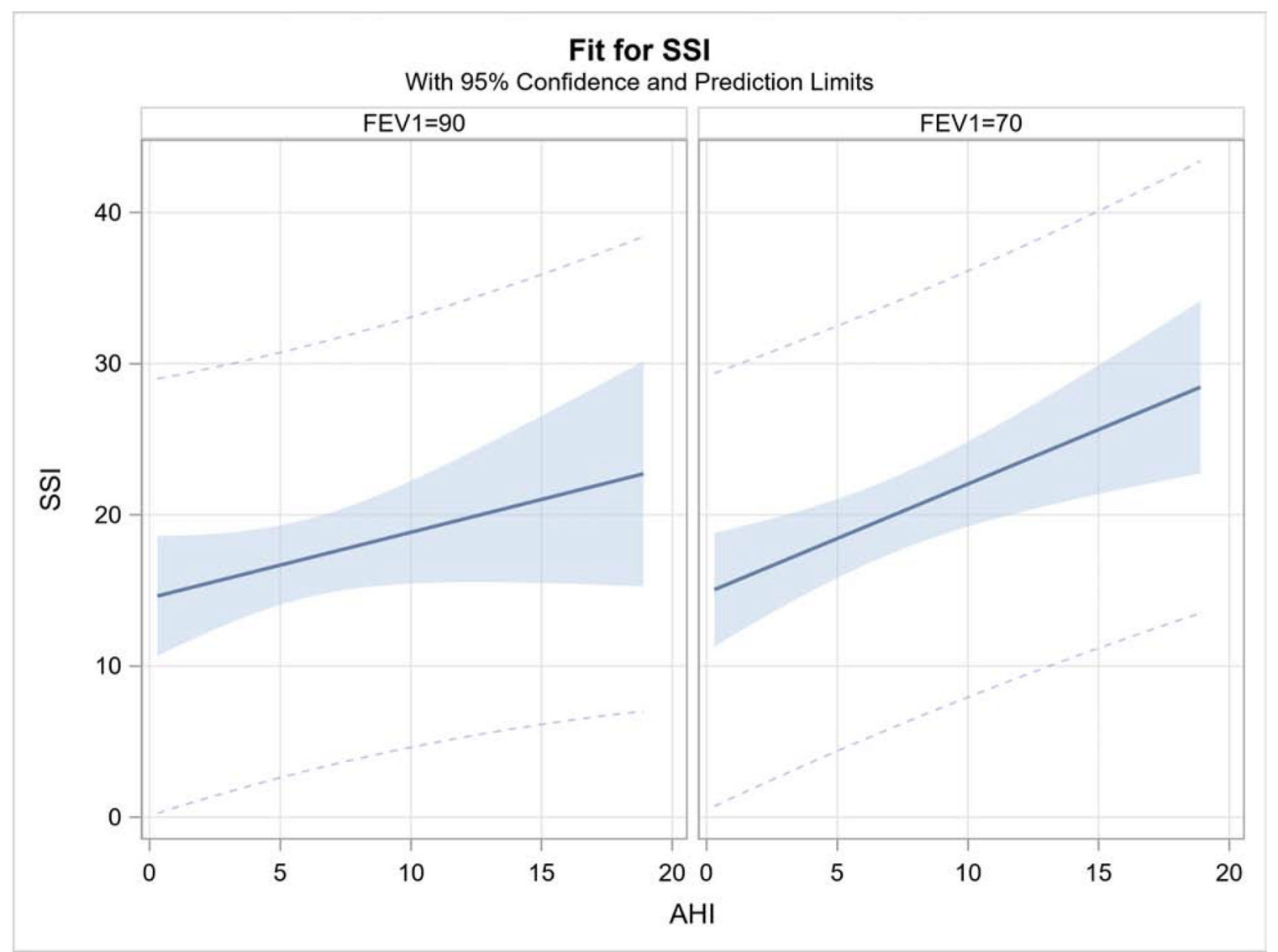

Figure 2: The influence of lung disease severity in the relationship between apnea-hypopnea index (AHI) and sleep-fragmentation among subjects with cystic fibrosis (CF).

This is a fit plot comparing the relationship between AHI and the Stage-Shifts Index (SSI) in subjects with low (FEV1 PPD=70\%) vs. normal (FEV1 PPD=90\%) lung function. For every 1-unit increase in AHI, the corresponding increase in the Stage-Shifts Index was higher in subjects with low vs. normal lung function $(\beta=-0.3, \mathrm{SE}=0.1, \mathrm{p}=0.047)$. 


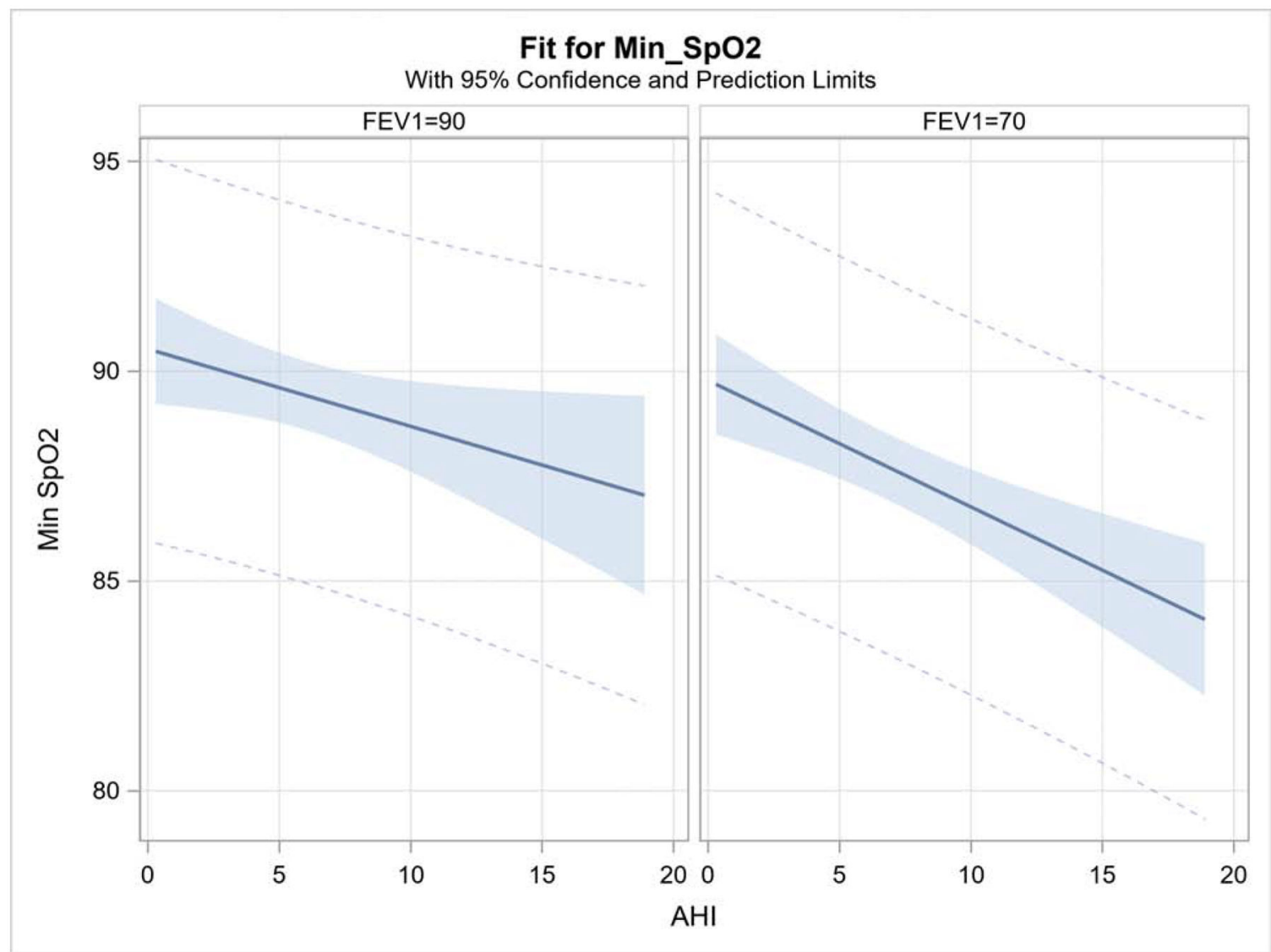

Figure 3: Influence of lung disease severity on the relationship between apnea-hypopnea index (AHI) and nocturnal oxygen saturation nadir.

This is a fit plot comparing the relationship between $\mathrm{AHI}$ and the Minimum $\mathrm{SpO}_{2}$ in subjects with low (FEV1 PPD=70\%) vs. normal (FEV1 PPD=90\%) lung function. For every 1-unit increase in AHI, the corresponding decrease in the Minimum $\mathrm{SpO}_{2}$ was lower in subjects with low vs. normal lung function $(\beta=0.12, \mathrm{SE}=0.04, \mathrm{p}=0.01)$. 
Table 1:

Baseline Demographics of CF and non-CF groups

\begin{tabular}{|cccc|}
\hline Characteristics & Cystic Fibrosis & Non-Cystic Fibrosis & P-Value \\
& Mean (SD) or \% & Mean (SD) or \% & \\
Adults & & \\
N & 23 & 46 & - \\
Age (years) & $35.9(12.9)$ & $36.0(12.8)$ & 0.98 \\
Gender (\% Male) & 52.2 & 52.2 & - \\
Race (\%White) & 100 & 100 & - \\
BMI (kg/m $\left.{ }^{2}\right)$ & $24.6(5.6)$ & $25.0(5.0)$ & 0.76 \\
& & & \\
N & 29 & 58 & - \\
Age (years) & $8.0(5.1)$ & $7.9(5.0)$ & 0.92 \\
Gender (\% Male) & 62.1 & 62.1 & - \\
Race (\%White) & 96.6 & 96.6 & - \\
BMI \%tile & $60.6(28.8)$ & $61.3(28.6)$ & 0.92 \\
\hline * & & & \\
two-sample t-test & & &
\end{tabular}

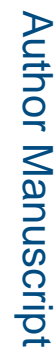


Table 2:

CF-specific Characteristics

\begin{tabular}{|cccc|}
\hline Characteristics & Adults & Children & P-Value \\
& Mean (SD) or \% & Mean (SD) or \% & \\
N & 23 & 29 & - \\
FEV1 PPD & $57.8(31.5)$ & $94.7(15.8)$ & 0.0003 \\
Brasfield Score & $17.0(3.1)$ & $19.2(2.0)$ & $0.07^{\#}$ \\
Sweat Chloride (mMol/L) & $99.0(16.5)$ & $100.3(19.7)$ & 0.82 \\
CF Genetics & & & $0.53^{\wedge}$ \\
\% deltaF508 homozygous & 52.2 & 37.9 & \\
$\%$ deltaF508 heterozygous & 39.1 & 55.2 & \\
\hline
\end{tabular}

two-sample t-test;

\# Wilcoxon rank sum test;

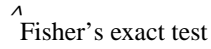


Table 3:

Standard polysomnographic measures of sleep and nocturnal gas-exchange in subjects with vs. without CF

\begin{tabular}{|c|c|c|c|}
\hline Variable & $\begin{array}{c}\text { Cystic Fibrosis } \\
\text { Mean (SD) }\end{array}$ & $\begin{array}{c}\text { Non-Cystic Fibrosis } \\
\text { Mean (SD) }\end{array}$ & P-Value* \\
\hline $\mathrm{N}$ & 52 & 104 & - \\
\hline Total Sleep Time (minutes) & $390.7(77.1)$ & $429.4(43.1)$ & $<0.0001$ \\
\hline Sleep-Onset Latency (minutes) & $26.6(28.4)$ & $19.4(18.7)$ & 0.04 \\
\hline Rapid Eye Movement (REM) Sleep Latency (minutes) & $153.3(89.2)$ & $144.5(83.9)$ & 0.53 \\
\hline Sleep Efficiency (\%) & $81.8(13.1)$ & $88.4(5.6)$ & $<0.0001$ \\
\hline WASO (minutes) & $58.8(52.6)$ & $38.0(26.3)$ & 0.0006 \\
\hline Arousal Index & $13.8(7.5)$ & $11.8(6.7)$ & 0.05 \\
\hline Stage-Shifts Index & $18.2(8.3)$ & $16.3(5.7)$ & 0.06 \\
\hline$\% \mathrm{~N} 1$ & $7.1(7.2)$ & $6.1(4.7)$ & 0.28 \\
\hline$\% \mathrm{~N} 2$ & $48.6(14.0)$ & $47.7(15.5)$ & 0.79 \\
\hline$\% \mathrm{~N} 3$ & $27.5(16.1)$ & $28.0(16.4)$ & 0.87 \\
\hline$\%$ REM & $17.4(8.4)$ & $18.1(6.4)$ & 0.52 \\
\hline Apnea-Hypopnea Index (AHI) ${ }^{* *}$ & $6.6(5.6)$ & $4.9(4.8)$ & 0.029 \\
\hline Obstructive Apnea Index (OAI) ${ }^{* *}$ & $0.1(0.2)$ & $0.2(0.5)$ & 0.1 \\
\hline Central Apnea Index (CAI) ${ }^{* *}$ & $0.9(1.4)$ & $0.7(1.3)$ & 0.5 \\
\hline Mean $\mathrm{SpO}_{2}(\%)$ & $94.7(2.4)$ & $96.3(1.3)$ & $<0.0001$ \\
\hline Minimum $\mathrm{SpO}_{2}(\%)$ & $88.7(3.9)$ & $90.5(3.6)$ & 0.0024 \\
\hline Percent total sleep time with low $\mathrm{SpO}_{2}$ & $2.2(7.5)$ & $0.09(0.3)$ & 0.0049 \\
\hline Duration of low $\mathrm{SpO}_{2}$ (minutes) & $6.2(20.1)$ & $0.4(1.5)$ & 0.0043 \\
\hline Maximum $\mathrm{CO}_{2}(\mathrm{mmHg})$ & $43.2(5.9)$ & $46.3(4.2)$ & 0.01 \\
\hline
\end{tabular}


Table 4:

Relationship between nocturnal gas-exchange parameters and daytime measures of CF lung disease severity

\begin{tabular}{|ccc|}
\hline Variable & FEV1PPD & Brasfield Scores \\
& Pearson R (P-Value) & Pearson R (P-Value) \\
$\mathrm{N}$ & 34 & 36 \\
Apnea-Hypopnea Index (AHI) & $-0.19(0.27)$ & $-0.16(0.36)$ \\
Mean $\mathrm{SpO}_{2}(\%)$ & $0.74(<0.0001)$ & $0.45(0.006)$ \\
Minimum $\mathrm{SpO}_{2}(\%)$ & $0.68(<0.0001)$ & $0.44(0.007)$ \\
Percent total sleep time with low $\mathrm{SpO}_{2}$ & $-0.42(0.01)$ & $-0.20(0.3)$ \\
Duration of low $\mathrm{SpO}_{2}($ minutes $)$ & $-0.43(0.01)$ & $-0.24(0.2)$ \\
Maximum $\mathrm{CO}_{2}(\mathrm{mmHg})$ & $0.01(0.96)$ & $-0.36(0.1)$ \\
\hline
\end{tabular}

